\title{
THE JUNE MEETING IN BELLINGHAM
}

The six hundred second meeting of the American Mathematical Society was held on Saturday, June 22, 1963 at Western Washington State College in Bellingham, Washington, in conjunction with a meeting of the Pacific Northwest Section of the Mathematical Association of America. There were 84 registrants at this meeting, 55 of whom were members of the Society.

By invitation of the Committee to Select Hour Speakers for Far Western Sectional Meetings, an hour address was given by Professor Errett Bishop of the University of California at Berkeley. Professor Bishop's address was entitled Some aspects of holomorphic convexity. Professor V. L. Klee introduced Professor Bishop.

There was one session for contributed papers with Professor Joseph Hashisaki presiding.

R. S. PIERCE

Associate Secretary 